\title{
DIGNIDADE DA PESSOA HUMANA NO CONTEXTO URBANO: O DIREITO A CIDADE
}

\section{Valter Foleto Santin ${ }^{1}$ Carolina Bombonatto Borchart ${ }^{2}$}

\section{RESUMO}

$\mathrm{Na}$ essência das inovações pertinentes ao direito urbanístico importante se faz assegurar o acesso da população aos direitos sociais destinados a assegurar real qualidade de vida. Ademais, empreende a demonstração da função social da cidade e da propriedade como garantidoras do direito à vida digna de forma a sustentar a ideia de que a efetivação plena do direito à cidade sustentável, aliado ao exercício da cidadania, podem trazer dignidade à vida das pessoas no espaço urbano. O intuito deste trabalho é exatamente almejar que a Política Urbana se desenvolva em harmonia entre entidades civis e anseios populares, garantindo direitos fundamentais. O método empregado é o dedutivo, por meio da pesquisa bibliográfica em livros e periódicos.

PALAVRAS-CHAVE: Direito urbano. Cidade sustentável. Função social. Dignidade da pessoa humana.

\section{DIGNITY OF THE HUMAN PERSON IN THE URBAN CONTEXT: THE RIGHT TO THE CITY}

\begin{abstract}
At the heart of the innovations relevant to important urban law is ensuring the population's access to social rights aimed at ensuring a real quality of life. In addition, it undertakes to demonstrate the social function of the city and property as guarantors of the right to a dignified life in order to support the idea that the full realization of the right to a sustainable city, together with the exercise of citizenship, can bring dignity to people's lives in urban space. The aim of this work is precisely to ensure that the Urban Policy develops in harmony between civil entities and popular aspirations, guaranteeing fundamental rights. The method used is the deductive method, through bibliographic research in books and periodicals.
\end{abstract}

KEY WORDS: Urban law. Sustainable city. Social function. Dignity of the human person.

\section{INTRODUÇÃO}

Aprioristicamente importa apresentar as razões, ainda que breves, da proposta do presente artigo de ressaltar os mecanismos criados para assegurar o acesso da população ao patrimônio mínimo destinado a permitir a esta uma vida digna e acesso aos direitos sociais destinados a assegurar uma boa qualidade de vida. E, para tanto, imprescindível à análise das

\footnotetext{
${ }^{1}$ Professor dos programas de Mestrado e Doutorado da Universidade Estadual do Norte do Paraná. Líder do Grupo de pesquisa Políticas públicas e efetivação dos direitos sociais (UENP).

${ }^{2}$ Mestranda em Ciência Jurídica pela Universidade Estadual Norte do Paraná - UENP. Participante do Grupo de pesquisa Políticas públicas e efetivação dos direitos sociais (UENP).
} 
inovações pertinentes ao direito urbanístico trazidas pelo Estado Democrático de Direito a Constituição Federal de 1988.

$\mathrm{O}$ artigo relacionando os objetivos e os fundamentos da cidadania e da dignidade da pessoa humana, presentes no artigo $1^{\circ}$ da Constituição Federal, que em conjunto consistem nos princípios fundamentais da República federativa do Brasil, enquanto Estado Democrático de Direito, examinando a premente primordialidade do Poder Público na integralidade de suas esferas em cumprir e almejar a implementação totalmente do direito urbano voltado à eficácia dos princípios constitucionais.

O estudo realiza os fundamentais conceitos à cidade sustentável seguindo pelos meandros de sua relação com o princípio da dignidade da pessoa humana.

Tomando-se como referência a organização da sociedade para finalidade de atingir objetivos comuns, voltada a uma vida cotidiana digna, houve a constatação de que não se pode permitir a existência de disparidades e carências de elementos essenciais para que esta se concretize. E, é nessa perspectiva que a dignidade da pessoa humana possui uma identificação tida como uma linha divisória que determina o limite para qualquer fato ou situação a ser considerado, atentedendo à busca do mínimo existencial inerente aos direitos sociais.

Feitas estas considerações, examinou-se a política urbana e suas condutas de desenvolvimento, para que sejam definidas de maneira a ordenar o pleno desenvolvimento das funções sociais da cidade e garantir o bem-estar de seus habitantes, atentando-se ao princípio de humanização da cidade.

O método de abordagem empregado é o dedutivo que permite partir de premissas gerais para se chegar a uma conclusão específica sobre os modelos aqui confrontados. Serviuse, no mais, do método dialético, com o objetivo de buscar possíveis sínteses para as divergências levantadas. Quanto ao procedimento, utiliza os métodos histórico, comparativo e sociológico, fazendo uso da interpretação sistemática. O tipo de pesquisa é o bibliográfico, a partir de livros e artigos científicos.

\section{A DIGNIDADE DA PESSOA HUMANA COMO PRINCÍPIO FUNDAMENAL}

Os princípios são constituídos no fundamento do ordenamento jurídico do Estado e, são considerados, valores normativos. Segundo Alexy (2008, p. 90) “princípios são mandamentos de otimização, normas que ordenam que algo seja realizado na maior medida possível”. Canotilho (2011, p. 1159-1175) salienta que os “princípios são normas de natureza 
estruturante ou com um papel fundamental no ordenamento jurídico devido à sua posição de hierarquia no sistema de fontes”. Os princípios são fundamentos, razão das regras jurídicas.

Nesta seara, a dignidade da pessoa humana é um preceito que possui o condão de unir, em maior ou menor grau, todos os direitos fundamentais dos quais os direitos do homem abrangem. Santos (1999, p. 97) aponta que é "o núcleo essencial dos direitos fundamentais". Sarlet (2012, p. 111) entende a dignidade da pessoa humana como "princípio basilar - mas não exclusivo - para a construção de um conceito material de direitos fundamentais". Flavia Piovesan (2013, p. 89) associa a dignidade da pessoa humana com a condição de legítimo "superprincípio constitucional", porque "simboliza a norma maior a orientar o constitucionalismo contemporâneo, dotando-lhe de especial racionalidade, unidade e sentido".

Os princípios que foram sendo, ao longo da história, objetivados e progressivamente introduzidos na consciência jurídica e se encontram recepcionados de forma implícita ou explicita no texto constitucional, são considerados "princípios jurídicos fundamentais" (CANOTILHO, 2011, p. 1165), os quais constituem a base para a interpretação, integração e aplicação das normas contidas na Constituição Federal.

A dignidade da pessoa humana é apreciada como uma norma que atinge notável posição no texto constitucional, sendo considerado princípio fundamental. Ademais, a expressão pessoa humana advém de um reconhecimento jurídico fundado em preceitos biológicos e filosóficos, distinguindo os seres humanos dos demais organismos vivos.

Por óbvio que a dignidade da pessoa humana está como fundamento essencial do Estado Democrático de Direito brasileiro que se perfaz pela efetivação dos vários direitos consagrados na Constituição, sendo que a "dignidade da pessoa humana é o fim supremo de todo o direito" (SILVA NETO, 2010, p. 259-274).

A Constituição Federal de 1988 instituiu em seu artigo $3^{\circ}$, como objetivos fundamentais da República Federativa do Brasil: a construção de uma sociedade livre, justa e solidária; a garantia do desenvolvimento nacional; a erradicação da pobreza e da marginalização e redução das desigualdades sociais e regionais; e a promoção do bem de todos, sem preconceitos de origem, raça, sexo, cor, idade e quaisquer outras formas de discriminação.

Relacionando os objetivos e os fundamentos da cidadania e da dignidade da pessoa humana, presentes no artigo $1^{\circ}$ da Constituição Federal, que em conjunto consistem nos princípios fundamentais da República federativa do Brasil, enquanto Estado Democrático de Direito, examina-se a premente primordialidade do Poder Público na integralidade de suas 
esferas em cumprir e almejar a implementação totalmente do direito urbano voltado à eficácia dos princípios constitucionais. A cidadania, por exemplo, presente no Art. $1^{\circ}$, II, da Constituição Federal está imediatamente ligada ao exercício absoluto dos direitos civis e políticos do cidadão brasileiro, até mesmo em questões que se concernentes às decisões de interesse de sua cidade.

Não se pode olvidar que o princípio da dignidade da pessoa humana possui ampla convergência com fundamentos que evidenciam os valores sociais do trabalho e da livre iniciativa, posto que a democracia social, tendo-se em vista a divisão espacial, o zoneamento urbano, a industrialização e o avanço do comércio são assuntos extremamente recorrentes no espaço das cidades.

Fato é que não há maneira de aceitar voluntariamene que o homem se distancie de componentes indispensáveis como: família, alimentação, habitação, emprego e integridade física. A sociedade deve se integrar de condições a reunir cuidados com fulcro na proteção recíproca, crescimento conjunto e evolução social.

Neste aspecto, a organização da sociedade não pode permitir a existência de disparidades e carências de elementos essenciais para a concretização da finalidade de atingir objetivos comuns, voltada a uma vida cotidiana digna, Carbonari (2007, p. 4) enfatiza que a própria dignidade é "qualidade intrínseca do ser humano e por isso esta não poderia ser separada ou retirada dele, existindo em cada pessoa como algo que lhe é próprio".

Constata-se que além de fundamento e fim da ordem jurídica, a dignidade é, sobretudo, pressuposto de igualdade real dos homens e da própria democracia. Assim, a noção de dignidade da pessoa humana está de maneira estrita relacionada à noção de justiça. Neste diapasão, não se pode falar em justiça sem atender a dignidade da pessoa humana.

Quando se convive em igualdade com os demais indivíduos, a pessoa humana, como ser social, tem o seu interesse obstado pela organização política da sociedade. Torna-se importante elucidar os dizeres de Guerra e Emerique (2006, p. 381), para os quais "a pessoa humana é considerada como indivíduo em sua singularidade".

A dignidade da pessoa humana possui uma identificação tida como uma linha divisória que determina o limite para qualquer fato ou situação a ser considerado.

\section{OS DIREITOS FUNDAMENTAIS SOCIAIS NOS CONTORNOS DA DIGNIDADE DA PESSOA HUMANA}


Eis que sobrevem o direito, norma reguladora, voltado a resolver os embates ocasionados pelas desigualdades, a fim de atingir a tão almejada paz social. No mais, de maneira a contrapesar as variadas condutas existentes socialmente, mostrar-se, portanto, a imprescindibilidade do Estado, instituição forte e organizada, que possui como suporte o direito.

Silva (2003, p. 285-286) visualiza os direitos sociais como ” dimensão dos direitos fundamentais do homem", prestações positivas estatais "enunciadas em normas constitucionais", para possibilitar "melhores condições de vida aos mais fracos", para realização da igualização de situações sociais desiguais", ligadas ao direito de igualdade, criando "condições materiais mais propícias ao aferimento da igualdade real" e compatibilidade com "o exercício efetivo da liberdade".

Spereta (2012, p. 65-66) anota que os direitos sociais "designam aquela parcela dos direitos de caráter eminentemente econômico", no sentido de "uma participação coletiva na produção econômica da sociedade", como educação, saúde e outros importantes parpa a sociedade.

Acca (2013, p. 43) expõe que “a expressão 'direitos sociais' pode abarcar uma quantidade considerável de tipos bastante diferentes de direitos, como direitos trabalhistas, direitos previdenciários, direito à saúde, à educação, à moradia e à assistência social”.

De outro lado, Costa (1990, p. 433) nos apresenta uma elucidação diversa de direitos sociais, demonstrando a ideia de que estes não são proteções para pessoas singulares apenas, e sim para uma coletividade:

O conceito de direitos fundamentais sociais, também conhecidos como direitos econômicos e culturais, significa a pretensão jurídica subjetiva, individual ou coletiva, a uma intervenção ativa do Estado, neste compreendido o aparato ou a sociedade civil, no sentido de se obter uma prestação ou uma regulamentação protetora.

A dignidade da pessoa humana tem interdependência com os direitos sociais prestacionais, conforme observa Ingo Sarlet (2012, p. 114), sem desconsiderar ou negar tal conexão "tanto mais intensa, quanto maior a importância dos direitos sociais para a efetiva fruição de uma vida com dignidade”, que são "dados variáveis de acordo com cada sociedade e em cada época”, em harmonia com a “dimensão histórico-cultural da própria dignidade da 
pessoa humana" e também dos "direitos fundamentais (inclusive sociais) que lhe são inerentes".

Clara e notória a relevância das bases fundamentais concernentes ao conceito da dignidade da pessoa humana, tanto quanto evidenciar sua correspondência com os direitos fundamentais, em especial aqueles com caráter social.

Segundo Fahd Awad (2006, p. 111-120):

Pode-se afirmar que o poder público, as instituições sociais e particulares, bem como a ordem jurídica, que não tratam com seriedade a questão da dignidade da pessoa humana não trata com seriedade os direitos fundamentais e, acima de tudo, não levam a serio a própria humanidade.

Nas palavras de Sarlet (2001, p. 152):

Parece-nos irrefutável que, na esfera das relações sociais, nos encontramos diuturnamente diante de situações nas quais a dignidade de uma determinada pessoa (e até mesmo de grupos de indivíduos) esteja sendo objeto de violação por parte de terceiros, de tal sorte que sempre se põe o problema teórico e prático - de saber se é possível, com o escopo de proteger a dignidade de alguém, afetar a dignidade do ofensor, que, pela sua condição humana, é igualmente digno, mas que, ao mesmo tempo naquela circunstância, age de modo indigno e viola a dignidade dos seus semelhantes, ainda que tal comportamento não resulte - como já anunciado alhures - na perda da dignidade.

Em razão da interdependência em que se almeja de preservar a dignidade humana concomitantemente a atingir os anseios dos direitos sociais, conclui-se que a efetivação desses é essencial para o exercício de direitos e liberdades fundamentais. O direito à vida, por exemplo, exige a eficácia do direito ao meio ambiente equilibrado, e o direito à dignidade reclama o direito à moradia, à educação, ao saneamento básico e outras contingências.

Os direitos sociais (COMPARATO, 2010, p. 77) "se realizam pela execução de políticas públicas, destinadas a garantir amparo e proteção social aos mais fracos e mais pobres; ou seja, aqueles que não dispõem de recursos próprios para viver dignamente ”. 
De fato, importante mencionar o conceito de "mínimo existencial", que nas palavras de Barroso (2011, p. 202) é "conjunto de condições materiais essenciais e elementares cuja presença é pressuposto da dignidade para qualquer pessoa. Se alguém viver abaixo daquele patamar, o mandamento constitucional estará sendo desrespeitado".

Vidal Serrano Nunes Junior trata dos direitos sociais e aponta a consolidação da "ideia de um mínimo existencial" (2009, p. 74), defendendo que a teoria da reserva do possível "é de aplicação excepcional", diante da realização de "direitos sociais que extrapolem o conceito de mínimo vital e que não estejam incorporados por normas constitucionais atribuivas de direitos públicos subjeitos a seus destinatários” (2009, p. 196).

Ana Paula de Barcellos (2002, p. 305) complementa ressaltando que "esse núcleo, no tocante aos elementos matérias da dignidade, é composto pelo mínimo existencial, que consiste em um conjunto de prestações mínimas sem as quais se poderá afirmar que o indivíduo se encontra em situação de indignidade".

Fala-se que respectivo mínimo existencial não deve aceitar o retrocesso (AGOSTINHO; BREGA FILHO, 2012, p. 257):

As conquistas alicerçadas no ordenamento jurídico não poderão ser objeto de mudanças em seu núcleo essencial, sem a criação de outros mecanismos compensatórios, sob pena de implicarem numa "revogação, anulação ou aniquilação" pura e simples deste núcleo, que deve ser o limite da atividade legislativa.

Ademais, mesmo que a Constituição brasileira não possua de maneira expressa a proibição de retrocesso, nos dizeres de Luis Otávio Vincenzi de Agostinho e Vladimir Brega Filho (2012, p. 252-253):

A Constituição brasileira não possui redação expressa em observância ao princípio da proibição de retrocesso social. A interpretação surge de forma implícita, por meio de uma análise do conteúdo material dos direitos fundamentais e sociais. [...] Portanto, o princípio da proibição de retrocesso, deverá sempre ser encarado como aliado da dignidade da pessoa humana, fundamento da República Federativa do Brasil, previsto no art. $1^{\circ}$, III da Constituição Federal, sendo que a partir desta 
análise, poderá se verificar se determinada modificação legislativa pode ou não ser considerada retrocesso.

Portanto, em obediência ao princípio da dignidade da pessoa humana, bem como aos Direitos Fundamentais consagrados pelo constituinte de 1988, o Estado tem a responsabilidade de assegurar aos indivíduos o absoluto exercício dos Direitos Sociais, para que possam viver com dignidade.

\section{O DIREITO URBANO E O SEU DESENVILVIMENTO EFICAZ}

É necessário zelar para que o desenvolvimento urbano não seja idealizado por meio de análises econômicas e interesses políticos, pois as consequências resultariam o desrespeito de direitos individuais e a diversidade de identidades e culturas existentes em uma mesma sociedade.

A política urbana concerne em um emaranhado de condutas, como transporte público, saneamento, calçamento, empregos, lazer, devendo integrar diversas políticas setoriais. Os objetivos da política de desenvolvimento urbano, definidos no texto constitucional, constituem em: ordenar o pleno desenvolvimento das funções sociais da cidade e garantir o bem-estar de seus habitantes.

Salinta Deilton Ribeiro Brasil e Maria Teresinha de Castro (2017, p. 207-208) que pensar em direitos fundamentais é sentir-se incorporado por direitos básicos:

Quando se fala em direitos fundamentais, vem a lume direitos basilares que se complementam e que num conjunto conduzem ao que buscamos em termos de dignidade da pessoa humana, o que incorpora direitos básicos como a sadia qualidade de vida, igualdade de direitos, democracia, saúde, educação, segurança, dentre outros de somenos importância, todos elencados da Constituição da República Federativa do Brasil. São direitos supremos e invioláveis inerentes e incorporados aos seres humanos.

É na cidade que o homem exaure o sua razão de viver e, em decorrência disso, necessário se faz valorizar a sua presença nesta localidade, isso se dá através do conjunto de procedimentos mediante os quais se efetiva a Política Urbana, pois além de almejar o 
progresso e os ideais de desenvolvimento, não se pode deixar de atentar-se ao princípio de humanizar a cidade.

Entende-se o sentido de que torna-se evidente que a responsabilidade municipal (LIMA; REIS, 2017, p. 210):

Com essas considerações torna-se evidente que a responsabilidade municipal no sentido de implantar políticas públicas voltadas aos direitos fundamentais de segunda geração, os chamados direitos sociais, devem ser efetivas e eficazes promovendo reais condições para o alcance e manutenção da vida humana com dignidade.

Deve-se comtemplar a importância de uma visão integradora entre as Políticas Urbanas e a cidade, visando à garantia e a efetividade dos direitos fundamentais.

Ademais, tamanha importância possui as politicas públicas efetivas (LIMA; REIS, 2017, p. 207):

A oferta de politicas públicas efetivas que busquem proteger os menos favorecidos devem realmente alcançar a finalidade pretendida, ou seja, garantir e proporcionar condições de acesso a saúde, educação, trabalho, lazer, segurança, previdência social, proteção à maternidade e à infância, assistência aos desamparados e moradia.

Um grande problema hodiarnamente a ser enfrentado está no crescimento desordenado da cidade, o qual reflete em profundas alterações nos direitos fundamentais sociais, que são majoradas em razão de ausência de um planejamento sustentável capaz de equilibrar a relação homem-dignidade.

Assim, de acordo com Santos (2008), a "recente urbanização brasileira, como fenômeno de concentração populacional urbana, fez surgir uma série de problemas socioeconômicos", como a carência de habitação e educação, desemprego, degradação ambiental, ausência de segurança pública e saneamento básico.

Manifesta-se, sobremaneira, a relevância do adequado exercício do direito de propriedade revertendo sua atenção aos interesses sociais, tanto quanto a execução de políticas públicas capazes de possibilitar o desenvolvimento digno das cidades. 
Nos dizeres de Kleinrath et al. (2012, p. 132) a função social da cidade, entendida como "o acesso à moradia, a equipamentos urbanos, ao transporte público, ao saneamento básico, à saúde, à educação, lazer, cultura e esportes", é resultado de um desenvolvimento urbano sustentável, direcionado à garantia de uma vida digna a todos os indivíduos.

Por decorrência lógica, a inexistência de políticas públicas convergentes ao desenvolvimento urbano gera, além de impactos ambientais, o fomento das diferenças sociais, especialmente no que diz respeito à exclusão das minorias.

Assim, claro e notório o quão importante e incontestável socialmente se mostram a função social da propriedade e a função social da cidade, as quais proporcionam a harmonização dos desenvolvimentos econômico e social com a preservação do direito social fundamental, assegurado os direitos essenciais dos cidadãos, entre eles o direito à infraestrutura urbana, à moradia, à saúde, à educação, ou seja, o direito à própria cidade.

Fala-se também da importância, como pressuposto da inclusão social e da preservação da natureza, do exercício do direito ao meio ambiente ecologicamente equilibrado e do direito à cidade, pois é por intermédio do equilíbrio entre desenvolvimento econômico e proteção do meio ambiente natural, à medida que ambos estão interrelacionados por dizerem respeito aos elementos essenciais à vida humana, que se encontra a qualidade de vida e a preservação do meio ambiente.

Isto posto, resta evidente que o desenvolvimento urbano, indiferente à função social da cidade, acarreta não só impactos de ordem natural, mas sobretudo, desigualdade social, nos termos destacados por Rangel e Silva (2009, p. 70):

As desigualdades sociais produzem a exclusão social e a marginalização de grupos sociais com baixo poder aquisitivo, fato que os distancia cada vez mais de uma moradia digna e do direito a uma cidade autossustentável. Tal conjuntura demonstra um apartheid e uma discriminação urbano-espacial. As desigualdades se tornaram tão patentes, que se estabeleceu uma segregação urbana, com a formação de duas cidades: "a legal" e a "informal".

Institui, dessarte, o necessário equilíbrio entre desenvolvimento urbano e garantia dos direitos sociais, que unicamente se mostram realizáveis por meio da função social da cidade, direcionada ao bem-estar de todos, bem como da atuação efetiva por parte do Poder 
Público, assegurando o pleno desenvolvimento das funções sociais da cidade, pressupostos do direito à uma vida digna.

\section{A PERCEPÇÃO DO DIREITO URBANO COMO INSTRUMENTO DE PRESERVAÇÃO DA VIDA HUMANA DIGNA}

Buscam os estudiosos a definição das cidades - por se manifestar nas mais diversas formas possíveis -, levando em consideração os diversos critérios que a mesma possui como, sendo estes: demográfico, o econômico e a pluralidade de sistemas (organizações públicas, comerciais, industriais). Tem-se a cidade como local essencialmente político, filosófico, cultural e social.

Interessante vislumbrar que todo o empenho jurídico doutrinário, no sentido de alcançar um conceito para cidade, encontra razão nas possíveis dimensões que os direitos imanentes às cidades podem provocar a partir da sua definição. Diante disso, à frente da divergência de algumas definições de cidade com a ordenação jurídica, é categórica a cooperação do jurista Celso Antonio Pacheco Fiorillo (2008, p. 300):

O meio ambiente artificial é compreendido pelo espaço urbano construído, consiste no conjunto de edificações (chamado de espaço urbano fechado), e pelos equipamentos públicos (espaço urbano aberto). Dessa forma, todos os espaços construídos bem como todos os espaços habitáveis pelo homem compõem o meio ambiente artificial.

Em sequência ao raciocínio alinhavado, por meio de uma explicação bastante adequada, elucida que o termo "urbano" reputa aos espaços habitáveis, ato contínuo possui em si o conceito de rural, este entendimento se associa aos princípios do direito fundamental ligado à cidade sustentável, uma vez que a plena obtenção à cidade sustentável se conduz a todos os espaços habitáveis, sendo assim, expõe Fiorillo (2009, p. 339):

Destarte, o termo "urbano" não evidencia um contraste com "campo" ou "rural", porquanto qualifica algo que se refere a todos os espaços habitáveis,

"não se opondo a rural, conceito que nele se contem; possui, possui, pois, uma natureza ligada ao conceito de território". 
Para ampliar o cenário jurídico-doutrinário é importante a contribuição proporcionada pelo jurista José Afonso da Silva (2008, p. 26) no sentido de elucidar sobre a concepção jurídica de cidade, como passa a reproduzir:

Todo centro populacional que possui unidades edilícias - ou seja, o conjunto de edificações em que os membros da coletividade moram ou desenvolvem suas atividades produtivas, comerciais, industriais ou intelectuais e equipamentos públicos - ou seja bens públicos e sociais criados para servir às unidades edilícias e destinados à satisfação das necessidades de que os habitantes não podem prover-se diretamente e por sua própria conta.

Com relação aos ensinamentos supracitados, conclui-se que o direito fundamental à cidade e ao território urbano não se restringe apenas aos espaços urbanizados, mas igualmente envolve o extenso acesso aos mecanismos urbanos nos espaços habitáveis, visando todos os cidadãos, independente de residirem nos espaços urbanizados ou rurais.

Nesse sentido, Janaína Rigo Santin e Ricardo Quinto Mattia (2007, p. 39), asseveram que o Direito Urbano "tem como objetivo ordenar o desenvolvimento das cidades como um todo, entendendo que os problemas urbanos não se dão de maneira isolada, mas sim que possuem ligação entre si e com a conjuntura do país".

Torna-se evidente a característica de universalidade da titularidade do direito fundamental à cidade e ao ambiente urbano, pois fato é sua destinação a todos os que estão sob o território das cidades brasileiras. Todo o ser humano possui direito à cidade, ou seja, possui direito urbano de acesso aos mecanismos assegurados pelo direito fundamental social, uma vez que, ter acesso ao saneamento básico, assistência médica, infraestrutura urbana não deve configurar-se privilégio das pessoas cujas residências se localizam em espaços considerados "urbanos e regulares", a todos pertence o direito á cidade.

Inclusive a discussão sobre o conceito de cidade participativa vem sendo estudada com grau de importância (OLIVEIRA; COLENCI, 2017, p. 11-12):

O conceito de cidade participativa, que se faz na participação das pessoas desde o quarteirão, o bairro, o Município, o Estado, a União. A pessoa tem que ter os palcos, os espaços para exercer a participação pública na gestão urbana, conectados numa rede de ação local. Com isso, o tripé do desenvolvimento sustentável, que se faz no econômico, social, ambiental, 
tendem a se equilibrar. Com a participação popular que as necessidades sociais e ambientais virão à tona e o econômico deixa de ser prevalente, tornando o espaço, mais social e ambiental e menos econômica.

No Brasil, a política de desenvolvimento urbano tem oferecido uma série de transformações paradigmáticas, rompendo com inúmeros padrões que, até então, dominavam a concepção jurídica de cidade. A cidade passa a ser assimilada na Ordem Jurídica como espaço cultural e coletivo, cuja atribuição é amparar aos interesses dos cidadãos com base nos princípios de justiça social, da função social da cidade e do direito fundamental social.

Importante salientar que a função social da cidade e suas orientações têm revigorado o Direito brasileiro e que, por meio do Direito Urbano, passou a representar instrumentos facilitadores do direito à cidade como Direito Fundamental.

Claro e evidente que os elementos caracterizadores do direito fundamental à cidade sustentável não se restringem apenas a expressar sua influência jurídica, política ou social, mas sobretudo, incentiva a reflexão sobre a cidade como espaço filosófico, no qual é concebível o desenvolvimento das potencialidades humanas e a realização de condições de vida digna para o ser humano.

Isto posto, enfrenta-se o desafio de transgredir com o delineamento das cidades brasileiras, que hodiernamente se baseiam na dualidade entre cidade legal e cidade ilegal, consequência da inexistência de canais democráticos de participação política no espaço das cidades, da carência de políticas públicas redistributivas, sustentáveis, inclusivas e no desrespeito à dignidade da pessoa humana.

O Direito Urbano possui como núcleo fundamental o direito à cidade sustentável, onde se encontram diversos direitos fundamentais, os quais não estão ligados apenas na construção de moradias para os mais carentes. Ele engloba inclusive, a efetivação de direitos civis e sociais, a exemplos do saneamento básico para toda a população e a proteção do meio ambiente equilibrado e sustentável, além de segurança pública ampla e competente e lazer disponível a todos.

Toda a preocupação jurídica e política concernente ao progresso das áreas urbanas e do direito à cidade sustentável, ultrapassa as esferas municipais, estaduais e federais passando a estimular o interesse internacional, pois um ambiente urbano que propicie vida digna aqueles que estão nele inseridos torna-se algo extremamente importante para o meio adequado à sobrevivência. 
O texto da Carta Mundial pelo Direito à Cidade, aprovada no Fórum Social Mundial em 2005, esclarece que o:

Direito à Cidade, definido como o usufruto equitativo das cidades dentro dos princípios de sustentabilidade e justiça social. É compreendido como um direito coletivo dos habitantes das cidades, em especial dos grupos vulneráveis e desfavorecidos que lhes confere a legitimidade de ação e organização com base nos seus usos e costumes, para obterem o pleno exercício do direito a um padrão de vida adequado [...]. O direito à cidade é interligado e interdependente a todos os direitos humanos internacionalmente reconhecidos, concebidos integralmente [...].

Com extremo valor e importância o direito à cidade sustentável preconiza uma nova maneira de se ponderar o espaço delineado a ela, fundamentando-se em instrumento de colaboração entre os diversos sujeitos que perfazem a sociedade, gestão democrática da cidade e dignidade da pessoa humana. Provoca uma sequência de modificações nos parâmetros de relações humanas, consumo, produção e apropriação do solo e dos recursos naturais. Os indivíduos transformam-se no cerne das preocupações, pleiteando às ações públicas nortear-se pelo absoluto direito a qualidade de vida para todos.

\section{DIREITO À CIDADE E OS DESAFIOS DA SUSTENTABILIDADE URBANA}

O progresso urbano, visando à garantia de uma cidade que atinja a vida humana com dignidade, buscando uma sadia qualidade de vida a todos, depreende do equilíbrio entre desenvolvimento econômico e preservação do meio ambiente.

No contexto do Estado Democrático de Direito no qual se insere o direito à cidade, tem-se o aperfeiçoameto pelo princípio da sustentabilidade urbana com abrangência a níveis e conceitos que refletem imediatamente na dignidade da pessoa à medida que almeja efetivar direitos fundamentais que proporcionam a superestimação das capacidades humanas nos espaços urbanos.

Logo, no elenco dos desafios relativos a viver em um ambiente em que prevaleça a dignidade da pessoa humana, é de fato importante salientar que há o envolvimento de indagações que abrangem a superação de adversidades sociais, como por exemplo, o anseio pela equiparação que carece existir entre os diversos aspectos sociais de poder, a inclusão Revista de Direito e Sustentabilidade | e-ISSN: 2525-9687 | Salvador | v. 4 | n. 1 | p. 39 - 58 | Jan/Jun. 2018 
cidadã das camadas sociais excluídas, e acima de tudo, o objetivo de colaborar na criação de uma identidade social que avançará no momento em que a população "urbana" puder ser reconhecida como formadora e decisiva destinatária da cidade e seus instrumentos.

De acordo com Fiorillo (2013, p. 79), o meio ambiente artificial "está diretamente relacionado ao conceito de cidade", compreendido, desta maneira, como a área urbana de convivência social, a qual realiza as atividades humanas e assegura os direitos fundamentais.

Verifica-se, hodiernamente, uma crescente desvalorização das questões ambientais e sociais tendo em vista o progresso urbano, com maior relevância no que concerne a destruição da natureza e falta de organização das respectivas políticas públicas. Disto resulta, por conseguinte, a deterioração da qualidade de vida na cidade.

Os espaços que pertencem às cidades foram criados com a finalidade de disponibilizar mecanismos capazes de fomentar adequadas condições de vida, o que tem causado elevada crise urbana, por atrair milhares de pessoas para as cidades. Por isso, o melhor que pode ser feito é encontrar meios para a alteração desse cenário, ao disponibilizar à população rural formas de aquisição a mecanismos antes exclusivo aos habitantes dos centros urbanos, acarretando desse modo o desenvolvimento humano estável relativo à dignidade da pessoa humana.

Portanto, a cidade não pode ser compreendida como um meio causador de impactos sociais, fruto da supervalorização dos direitos individuais sobre os direitos sociais, mas precisa ser desenvolvida como meio a assegurar o direito a uma vida digna com a qual se manifesta claramente a sua função social, que, nos dizeres de Fiorillo (2013, p. 550) é:

Cumprida quando esta proporciona a seus habitantes o direito à vida, à segurança, à igualdade, à propriedade e à liberdade (CF, art. 5\%, caput), bem como quando garante a todos um piso vital mínimo, compreendido pelos direitos sociais à educação, à saúde, ao lazer, ao trabalho, à previdência social, à maternidade, à infância, à assistência aos desamparados, entre outros encartados no art. $6^{\circ}$.

Machado (2008) relata que o homem tem direito a adequadas condições de vida, em um meio ambiente de qualidade, sendo direito fundamental do homem o respeito à sua dignidade como cidadão, fazendo-se necessária a adoção de medidas capazes de atender a esses princípios, consagrados pela Constituição da República Federativa do Brasil. 
De acordo com Paulo Afonso Cavichioli Carmona (2010, p. 21), existem dez grupos de recomendações para um desenvolvimento sustentável como parte integrante do processo de planejamento da cidade, são eles:

1. Garantir uma cidade para todos; 2. promover a participação efetiva; 3. valorizar uma cidade para todos; 4. garantir a continuidade na vocação das cidades; 5. destacar os benefícios das novas tecnologias; 6. estimular a sustentabilidade do meio ambiente; 7. combinar os aspectos físicos com os sociais e econômicos; 8. contemplar uma gestão do tráfego de forma a garantir a mobilidade e a acessibilidade; 9. promover variedade e diversidade com o abandono das grandes zonas aos monofuncionais; e 10. tutelar as questões envolvendo saúde e segurança, incorporando medidas de proteção contra as catástrofes naturais, criminalidade e conflitos sociais.

Nesse sentido, resta claro que não há como progredir os anseios a um desenvolvimento sustentável da sociedade sem antes propiciar às cidades uma infraestrutura mínima capaz de assegurar aos indivíduos uma vida digna.

Algo que se mostra importante é a participação do cidadão na gestão urbana, em mecanismo de democracia participativa urbanística, com base no Estatuto da Cidade e das resoluções do Conselho das Cidades, como mecanismo de busca de sustentatilidade, entre o desenvolvimento e natureza, coforme aduz Luciana C. Poli e Bruno F. Hazan (2016, p. 111):

Há que se transformarem as consciências individuais sobre a reprodução de práticas sociais de forma a propiciar a promoção da participação ampla na elaboração do orçamento. As decisões orçamentárias devem avançar no sentido de conferir oportunidades coletivas, pautadas em estratégias dos diversos interessados, voltadas a atingir objetivos metaindividuais de longo prazo.

Anotam Celso Maran de Oliveira e Pedro Luciano Colenci (2017, p. 12) defendem que a "proprocionar melhor qualidade de vida aos citadinos é função não centralizada ou mesmo exclusiva do Poder Público", por necessidade de "condução e discussão de políticas públicas juntamente com os destinatários”, para que a política pública possa ser chamada de "democrática", refletindo na própria legalidade. 
A sustentabilidade tem íntima ligação com a segurança pública do cidadão, acossado pela criminalidade urbana, observando as palavras de Valter Foleto Santin (2005, p. 211) que:

O ser humano tem interesse de viver em ambiente social ordeiro e que a sua vida, saúde e patrimônio sejam respeitados pelos semelhantes e pelo Estado, em situação de predomínio de "interesse difuso" de preservação destes valores em relação ao indivíduo, ao grupo e todas as pessoas em geral, para a manutenção do equilíbrio da sociedade e da ordem pública pelo serviço de segrunça pública.

É premente estabelecer a sustentabilidade urbana como condição necessária ante a atual crise urbana difundida nos mais variados espaços citadinos. Delinear a construção das cidades e procurar alternativas para impulsionar o equilíbrio que demanda o conceito de cidade sustentável é o grande desafio a ser ultrapassado pelos atores sociais do atual século.

\section{CONSIDERAÇÕES FINAIS}

A dignidade da pessoa humana é apreciada como uma norma que atinge notável posição no texto constitucional, sendo considerado princípio fundamental.

Quando se convive em igualdade com os demais indivíduos, a pessoa humana, como ser social, tem o seu interesse obstado pela política da sociedade.

Em razão da interdependência em que se almeja de preservar a dignidade humana concomitantemente a atingir os anseios dos direitos sociais, conclui-se que a efetivação desses é essencial para o exercício de direitos e liberdades fundamentais.

Para tanto, deve-se comtemplar a importância de uma visão integradora entre as Políticas Urbanas e a cidade, visando à garantia e a efetividade dos direitos fundamentais. $\mathrm{O}$ direito, com fim à garantia da ordem e da paz social, enquanto sistema de normas tendentes a regulação da conduta humana, não pode isentar-se das demandas consequentes ao desenvolvimento urbano, devendo atuar com foco na efetivação do princípio constitucional da dignidade da pessoa humana, em particular, os munícipes e citadinos.

Sabe-se que o espaço urbano brasileiro tem extrema correlação com a estrutura econômica do país e sua formação social. 
Assim, claro e notório o quão importante e incontestável socialmente se mostram a função social da propriedade e a função social da cidade, as quais proporcionam a harmonização dos desenvolvimentos econômico e social com a preservação do direito social fundamental, assegurado os direitos essenciais dos cidadãos, entre eles o direito à infraestrutura urbana, à moradia, à saúde, à educação, ou seja, o direito à própria cidade.

A cidade é direito que pertence a todos que nela habitam e que devem fazer jus a viver em um ambiente sadio.

Com extremo valor e importância o direito à cidade sustentável preconiza uma nova maneira de se ponderar o espaço delineado a ela, fundamentando-se em instrumento de colaboração entre os diversos sujeitos que perfazem a sociedade, gestão democrática da cidade e dignidade da pessoa humana. Provoca uma sequência de modificações nos parâmetros de relações humanas, consumo, produção e apropriação do solo e dos recursos naturais.

Esse diagnóstico demonstra que o Município deve-se revestir de políticas públicas voltadas para o planejamento urbano, criando políticas públicas reais, voltadas ao atendimento das necessidades dos cidadãos.

É imperativo que não há como progredir os anseios a um desenvolvimento sustentável da sociedade sem antes propiciar às cidades uma infraestrutura mínima capaz de assegurar aos indivíduos uma vida digna.

\section{REFERÊNCIAS}

AGOSTINHO, Luis Otávio Vincenzi de; BREGA FILHO, Vladimir. A proibição de retrocesso e a reforma do Código Florestal. Argumenta Journal Law, Jacarezinho - PR, n. 16, 2012, p. 247-265. ISSN 2317-3882.2012. Disponível em: <https://seer.uenp.edu.br/index.php/argumenta/article/view/222/221>. Acesso em: 06 abr. 2018.

AWAD, Fahd. O princípio constitucional da dignidade da pessoa humana. Justiça do Direito, Passo Fundo, v. 20, n. 1, 2006.

BARCELLOS, Ana Paula de. A eficácia jurídica dos princípios constitucionais: o princípio da dignidade da pessoa humana. Rio: Renovar, 2002.

BARROSO, Luís Roberto. Curso de Direito Constitucional Contemporâneo: os conceitos fundamentais e a construção do novo modelo. $3^{\mathrm{a}}$ ed., São Paulo: Saraiva, 2011.

BRASIL, Deilton Ribeiro; CASTRO, Maria Teresinha de. Proteção do meio ambiente e sustentabilidade como caminhos para a efetivação do Direito Fundamental à qualidade 
de vida. In: XXVI Congresso Nacional do CONPEDI. Direito e sustentabilidade I.

Organização CONPEDI. Coordenadores: Flavia Piva Almeida Leite; Jackson Passos Santos. Florianópolis: CONPEDI, 2017. Disponível em:

<https://www.conpedi.org.br/publicacoes/27ixgmd9/q0t86psl/QMSj5pSJkLy8TWP5.pdf>.

Acesso em: 06 abr. 2018.

CARMONA, P. A. C. Direito Urbanístico. São Paulo: Saraiva, 2010.

COMPARATO, Fábio Konder. A Afirmação Histórica dos Direitos Humanos. $7^{\text {a }}$ ed., São Paulo: Saraiva, 2010.

FIORILLO, Celso Antonio Pacheco. Curso de direito ambiental brasileiro. 14. ed., São Paulo: Saraiva, 2013.

KLEINRATH, Stella de Moura et al. Cidades: sustentabilidade e mecanismos de ordenação urbana. In: RIOS, Mariza et al. (Coord.). Direito à cidade: moradia e equilíbrio ambiental. Belo Horizonte: Del Rey, 2012.

LEFF, Enrique. Complexidade, interdisciplinaridade e saber ambiental. In: PHILIPPI JÚNIOR, Arlindo et al. Interdisciplinaridade em ciências ambientais. São Paulo: Signus, 2000.

LIMA, Francelise Camargo de; REIS, Clayton. A aplicação da responsabilidade civil em face do Município pela inacessibilidade dos direitos sociais. In: XXVI Congresso Nacional do CONPEDI. Direito administrativo e gestão pública II. Organização CONPEDI, Coordenadores: Mateus Eduardo Siqueira Nunes Bertoncini; José Sérgio da Silva Cristóvam - Florianópolis: CONPEDI, 2017, p. 195-213. Disponível em:

<https://www.conpedi.org.br/publicacoes/27ixgmd9/ihjf0v9g/6wVaHJ5UxE0G1ifm.pdf>. Acesso em: 05 abr. 2018.

MACHADO, Paulo Affonso Leme. Direito Ambiental brasileiro. 16a . ed., São Paulo: Malheiros, 2008.

MARQUES, José Roberto. Meio ambiente urbano. 2. ed., Rio de Janeiro: Forense, 2010.

NUNES JUNIOR, Vidal Serrano. A cidadania social na Constituição de 1.988: Estratégias de positivação e exigibilidade judicial dos diretios sociais. São Paulo: Verbatim, 2009.

OLIVEIRA, Celso Maran de; COLENCI, Pedro Luciano. Função social da cidade: cidades participativa. In: XXVI Congresso Nacional do CONPEDI. Direito urbanístico, cidade e alteridade. Organização CONPEDI, Coordenadores: Edson Ricardo Saleme, Mônica da Silva Cruz, Joaquim Shiraishi Neto. Florianópolis: CONPEDI, 2017, p. 6-23. Disponível em <https://www.conpedi.org.br/publicacoes/27ixgmd9/m4wq16h3/3h3CM45KKA6Lj7EO.pdf>. Acesso em: 05 abr. 2018.

POLI, Luciana C., HAZAN, Bruno F. Políticas públicas de conhecimento: redefinindo a lógica do orçamento. Argumenta Journal Law, Jacarezinho - PR, Brasil, n. 24, jan/jun 2016, p. 99-119. Disponível em < 
http://seer.uenp.edu.br/index.php/argumenta/article/viewFile/433/pdf>. Acesso em: 05 abr. 2018.

RANGEL, Helano Márcio Vieira; SILVA, Jacilene Vieira da. O direito fundamental à moradia como mínimo existencial e a sua efetivação à luz do Estatuto da Cidade.

Veredas do Direito: Direito Ambiental e Desenvolvimento Sustentável, Belo Horizonte, v. 6, n. 12, 2009.

SANTIN, Janaína Rigo; MATTIA, Ricardo Quinto. Direito Urbanístico e Estatutos das Cidades. Revista de Direito Imobiliário, Ano 30, nº 63. São Paulo: Revista dos Tribunais, 2007.

SANTIN, Valter Foleto. Característica de direito ou interesse difuso da segurança pública. Argumenta Journal Law, Jacarezinho - PR, n. 5, p. 208-216, 2005. ISSN 23173882. Disponível em: <http://seer.uenp.edu.br/index.php/argumenta/article/view/48/49>. Acesso em: 05 abr. 2018.

SANTOS, Milton. A urbanização brasileira. $5^{\text {a }}$ ed., São Paulo: Universidade de São Paulo, 2008.

SARLET, Ingo Wolfgang. Dignidade da pessoa humana e direitos fundamentais na Constituição Federal de 1988. 9. ed., Porto Alegre: Livraria do advogado, 2012.

SILVA, Carlos Henrique Dantas da. Plano diretor: teoria e prática. São Paulo: Saraiva, 2008. 